\title{
Elevated PD-L1 expression predicts poor survival outcomes in patients with cervical cancer
}

\author{
Xiaobin Gu, Meilian Dong, Zheyan Liu, Yin Mi, Jing Yang, Zhigang Zhang, Ke Liu, Li Jiang, Yue Zhang, \\ Shiliang Dong and Yonggang Shi
}

\begin{abstract}
Background: Programmed cell death ligand 1 (PD-L1) expression has been shown to associate with poor prognosis in a variety of solid tumors. However, the prognostic value of PD-L1 expression in cervical cancer is still controversial. Therefore, we carried a meta-analysis to investigate the prognostic and clinicopathological impact of PD-L1 in cervical cancer.

Methods: A comprehensive literature search in was performed in PubMed, Embase, Web of Science, and Cochrane Library. The correlation between PD-L1 expression and overall survival (OS), progression-free survival (PFS), and clinicopathological features was analyzed by hazard ratios (HR), odds ratios (OR) and corresponding 95\% confidence intervals $(\mathrm{Cl})$.

Results: Seven studies with 783 patients were included in this meta-analysis. The combined HR and 95\% Cl of OS was 2.52 (1.09-5.83), $p=0.031$. The pooled results for PFS were $H R=2.07,95 \% \mathrm{Cl}=0.52-8.23, p=0.302$. The results of subgroup analysis showed that PD-L1 was a significant prognostic factor of poor OS in Asian patients (HR $=4.77,95 \%$ $\mathrm{Cl}=3.02-7.54, \mathrm{p}<0.001)$ and of poor PFS in Asian patients $(\mathrm{HR}=4.78,95 \% \mathrm{Cl}=1.77-12.91, \mathrm{p}=0.002)$. However, the pooled results suggested that PD-L1 was not significantly correlated with lymph node metastasis, tumor size, FIGO stage, depth of invasion, lymph-vascular invasion, or age.

Conclusions: The results of this meta-analysis suggest that PD-L1 overexpression is related to poor OS in patients with cervical cancer and poor PFS in Asian patients with cervical cancer. This study also suggests that PD-L1 is a promising prognostic indicator for cervical cancer.
\end{abstract}

Keywords: Cervical cancer, PD-L1, Meta-analysis, Prognosis

\section{Background}

Cervical cancer is the fourth most common malignancy and the fourth leading cause of cancer-related deaths in females globally [1]. In 2018, it is estimated that 569,847 new cases of cervical cancer are diagnosed and 311,365 cases died from this disease worldwide [1]. With the improvement of new diagnostic techniques and therapeutic strategies, the incidence rates of cervical cancer

\footnotetext{
*Correspondence: fccshiyg@zzu.edu.cn
}

Department of Radiation Oncology, The First Affiliated Hospital

of Zhengzhou University, Zhengzhou University, Zhengzhou 450000,

Henan, People's Republic of China have declined significantly in developed countries, however, the mortality is still high in developing countries. Approximately $90 \%$ of cervical cancer deaths occurred in low income and middle-income countries (LMIC) [2]. Although several prognostic biomarkers have been identified, such as lymph node status, tumor size and tumor stage, those biomarkers lack specificity and sensitivity for accurate prediction. Therefore, it is urgently needed to identify many novel and feasible prognostic markers to guide personalized treatment and predict survival outcomes of cervical cancer patients.

Programmed death-ligand 1 (PD-L1 or B7-H1) is the major ligand for programmed cell death protein 1 (PD-1). 
PD-L1 is expressed in immune cells, including activated $\mathrm{T}$ cells, B cells, dendritic cells, macrophages, and various tumor cells [3]. Normally, PD-L1 expression maintains the homeostasis of the immune response. In the healthy immune system, the activation of the PD-1/PD-L1 pathway can limit autoimmunity and inhibit the activity of $\mathrm{T}$ lymphocytes under an inflammatory response to infection [4]. In tumor microenvironment, cancer cells and infiltrating immune cells express PD-L1, which binds to PD- 1 on $\mathrm{T}$ cells and then suppress the proliferative and effector responses of $\mathrm{T}$ cells $[5,6]$. The prognostic value of PD-L1 in various have been investigated, such as breast cancer [7], non-small cell lung cancer [8], pancreatic cancer [9], renal cell carcinoma [10], and gastric cancer [11]. However, the prognostic value of PD-L1 in cervical cancer is still conflicting [12-15]. Therefore, we collected eligible data and conducted a meta-analysis to reveal the prognostic and clinical significance of PD-L1 in cervical cancer.

\section{Methods}

\section{Literature search strategy}

This meta-analysis was performed according to Preferred Reporting Items for Systematic Reviews and Meta-Analyses (PRISMA) Statement [16]. Relevant studies were searched from online databases PubMed, EMBASE, Web of Science, and, Cochrane Library up to Feb, 2019. The following keywords in combination with Medical Subject Headings (MeSH) terms and free words were used: "PDL1", "programmed cell death ligand 1", "B7-H1", "CD274", "cervical carcinoma", and "cervical cancer". References in the retrieved articles and preceding reviews were also manually searched to identify relevant studies.

\section{Inclusion and exclusion criteria}

Qualified studies need to meet the following inclusion criteria: [1] all patients were diagnosed as cervical cancer by pathological findings; [2] immunohistochemistry (IHC) was used to detect PD-L1 expression in tissues; [3] the relationship between PD-L1 expression and overall survival (OS) and/or progression-free survival (PFS) were provided or sufficient information was provided to estimate the hazard ratio (HR) with Tierney's method [17]; [4] number of patients was more than 20; [5] the expression of PD-L1 was categorized into high (positive) and low (negative) groups; [6] English or Chinese articles. The exclusion criteria were as follows: [1] reviews, case reports, meeting abstracts, or letters; [2] animal studies; [3] overlapping studies.

\section{Data extraction and quality assessment}

Two investigators (X.B., Gu and M.L., Dong) independently extracted the following information from the included studies: author, year of publication, country, number of patients, age, treatment, The International Federation of Gynecology and Obstetrics (FIGO) stage, study period, the hazard ratios (HRs) and 95\% confidence intervals (CIs) for OS and PFS. Disagreements between the investigators were resolved through discussion. The quality of the selected articles was assessed according to the Newcastle-Ottawa Scale (NOS) [18]. The NOS scale consists of three factors: patient selection, comparability, and assessment of outcome. Total quality scores were ranged from 0 to 9 and studies with the final score $>6$ were regarded as high-quality studies.

\section{Statistical analysis}

The HRs and $95 \%$ CIs of each study were combined to evaluate the relationship between PD-L1 expression and the prognosis. The pooled odds ratio (OR) and 95\% CI was used to assess the correlation between the PD-L1 expression and clinicopathological characteristics. Heterogeneity among studies was evaluated using Cochrane's $\mathrm{Q}$ tests (Chi squared tests) and the $I^{2}$ metric. Significant heterogeneity was defined as $\mathrm{p}<0.05$ for the $\chi^{2}$ test or $I^{2}>50 \%$ and then a random effects model was used for calculation, otherwise, a fixed effects model was applied. The potential for publication bias was assessed using the Begg's funnel plot [19] and the Egger linear regression test [20]. All above calculations were performed using Stata version 12.0 (Stata Corporation, College Station, TX, USA). A $\mathrm{p}<0.05$ was considered as statistically significant.

\section{Results}

\section{Literature selection and study characteristics}

A total of 499 studies were identified through initial literature search. After duplicate records were removed, 387 studies were left. After title and/or abstracts screening, 29 articles remained for full-text assessment. By full text examination, 22 studies were excluded with various reasons. At last, 7 studies [12-15, 21-23] were included for the final meta-analysis. The detailed diagram of the above screening process is shown in Fig. 1. All 7 eligible studies were retrospective studies published between 2009 and 2018. The sample size ranged from 27 to 219 and the total sample size was 783 . Three studies were conducted in China [21-23], and one in USA [12], Canada [13], Korea [14], and Japan [15], respectively. All 7 studies provided the data between PD-L1 and OS, and 3 studies [13, 14, 23] presented information for PD-L1 and PFS. Six studies $[12-15,22,23]$ were published in English and one [21] was published in Chinese. The NOS scores of included studies ranged from 6 to 8 , with a mean value of 7 . The characteristics of the 7 eligible studies were shown in Table 1. 

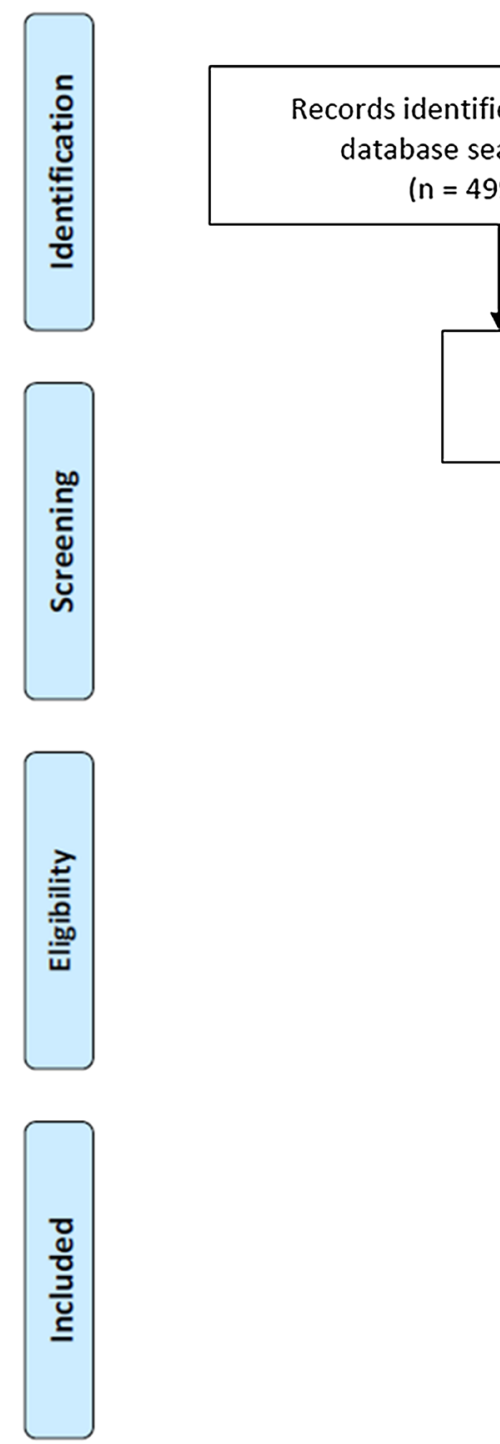

cords identified through ase searching

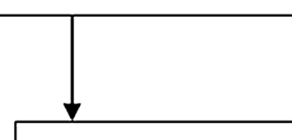

Records after duplicates removed

$(n=387)$

Additional records identified through other sources $n=0$ )
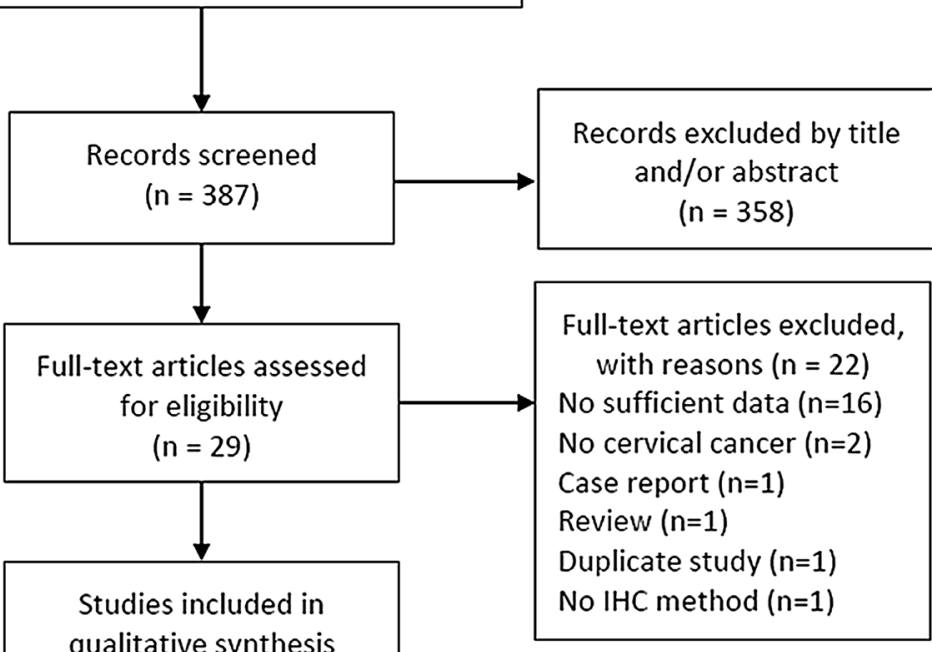

qualitative synthesis $(n=7)$

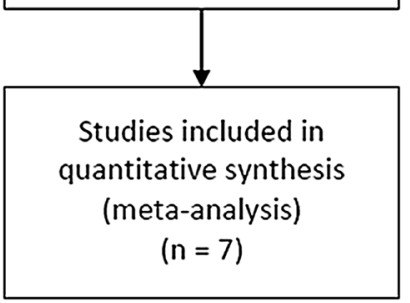

Fig. 1 Flow chart for selection of studies

Table 1 Basic characteristics of included studies

\begin{tabular}{|c|c|c|c|c|c|c|c|c|c|c|}
\hline Author & Year & Country & No. of patients & Age (year) & Treatment & FIGO stage & $\begin{array}{l}\text { Detection } \\
\text { method }\end{array}$ & Study period & Survival analysis & NOS score \\
\hline Karim & 2009 & USA & 115 & $46.5(24-87)$ & Surgery & $|-| \mid$ & $\mathrm{IHC}$ & 1985-1999 & OS & 7 \\
\hline Duan & 2017 & China & 64 & $47.5(30-65)$ & Surgery & $\mid-\| A$ & $\mathrm{IHC}$ & 2013-2015 & OS & 6 \\
\hline Enwere & 2017 & Canada & 120 & $44(39-49)$ & CCRT & IB-IVA & $\mathrm{IHC}$ & 1999-2008 & OS, PFS & 7 \\
\hline Kim & 2017 & Korea & 27 & $46(34-71)$ & Surgery & $|\mathrm{B} 1-| \mid \mathrm{A}$ & $\mathrm{HC}$ & $2011-2012$ & OS, PFS & 8 \\
\hline Feng & 2018 & China & 219 & $49(26-75)$ & Mixed & I-IV & $\mathrm{HC}$ & $2013-2016$ & OS & 7 \\
\hline Kawachi & 2018 & Japan & 148 & $45(30-72)$ & Surgery & $|-| \mid$ & $\mathrm{HC}$ & $2001-2014$ & OS & 7 \\
\hline Wang & 2018 & China & 90 & $46(23-71)$ & Surgery & $|B 1-| \mid A 2$ & $\mathrm{HHC}$ & 2009-2012 & OS, PFS & 7 \\
\hline
\end{tabular}

CCRT, concurrent chemo-radiotherapy; IHC, immunohistochemistry; OS, overall survival; PFS, progression-free survival; NOS, Newcastle-Ottawa scale 


\section{Association between PD-L1 expression and OS, PFS}

All 7 included studies [12-15, 21-23] presented the correlations between PD-L1 and OS. The pooled HR and $95 \% \mathrm{CI}$ of OS was $2.52(1.09-5.83), \mathrm{p}=0.031$. The heterogeneity was not significant $\left(I^{2}=73 \%, \mathrm{p}=0.001\right)$ therefore the random-effects model was used (Fig. 2). Three studies [13, 14, 23] reported the associations between PD-L1 and PFS. As shown in Fig. 3, the results were $\mathrm{HR}=2.07,95 \% \mathrm{CI}=0.52-8.23, \mathrm{p}=0.302$, the random-effects model was applied because of significant heterogeneity $\left(I^{2}=77.2 \%, \mathrm{p}=0.012\right)$.

\section{Subgroup analysis}

To further investigate the prognostic value of PD-L1 in different subpopulations, the subgroup analysis was conducted. The subgroup analysis was performed based on the following factors: ethnicity (Asian or Caucasian), sample size $(<100$ or $\geq 100)$, and treatment (surgery or non-surgery). The results showed that high expression

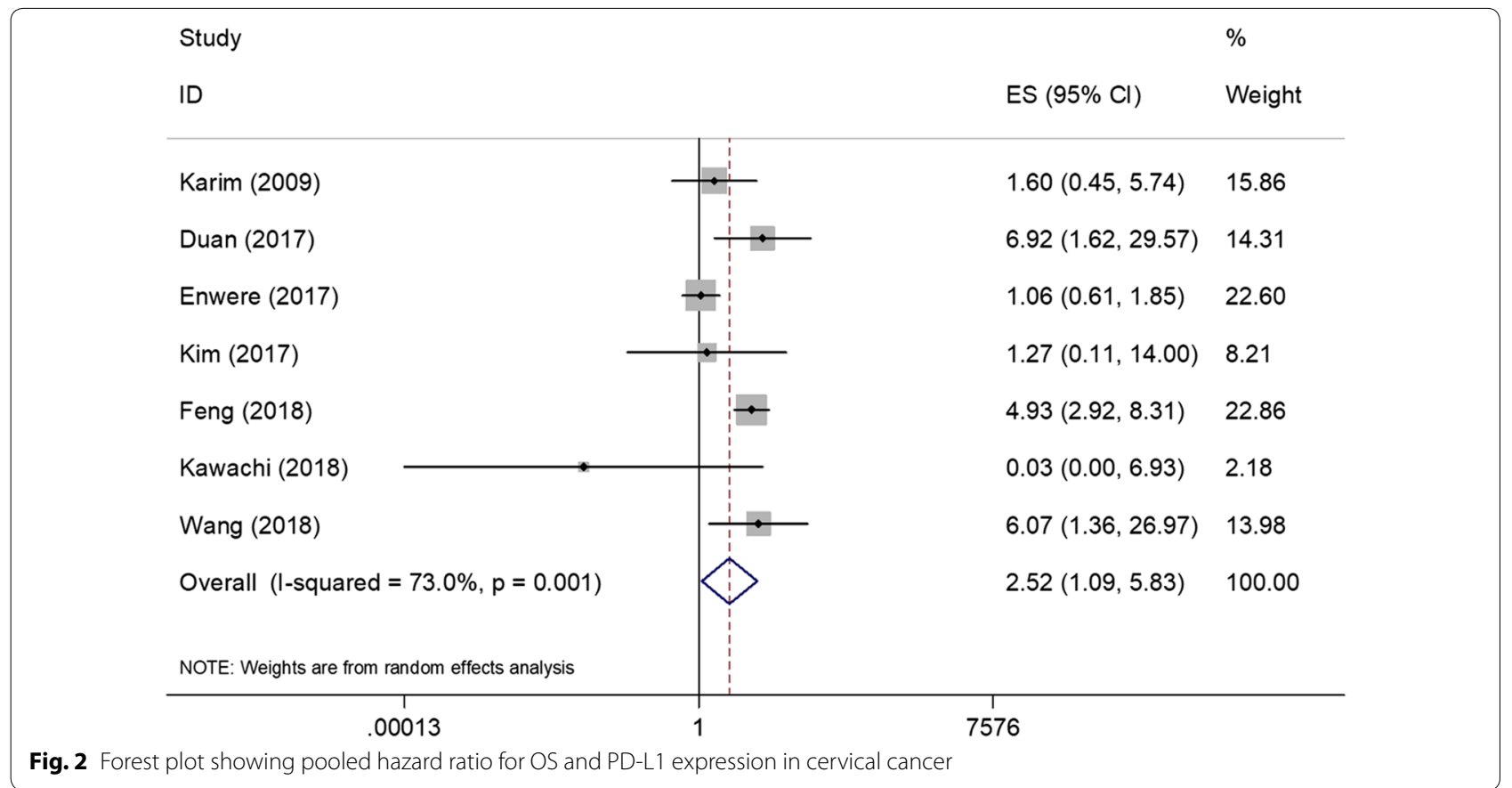

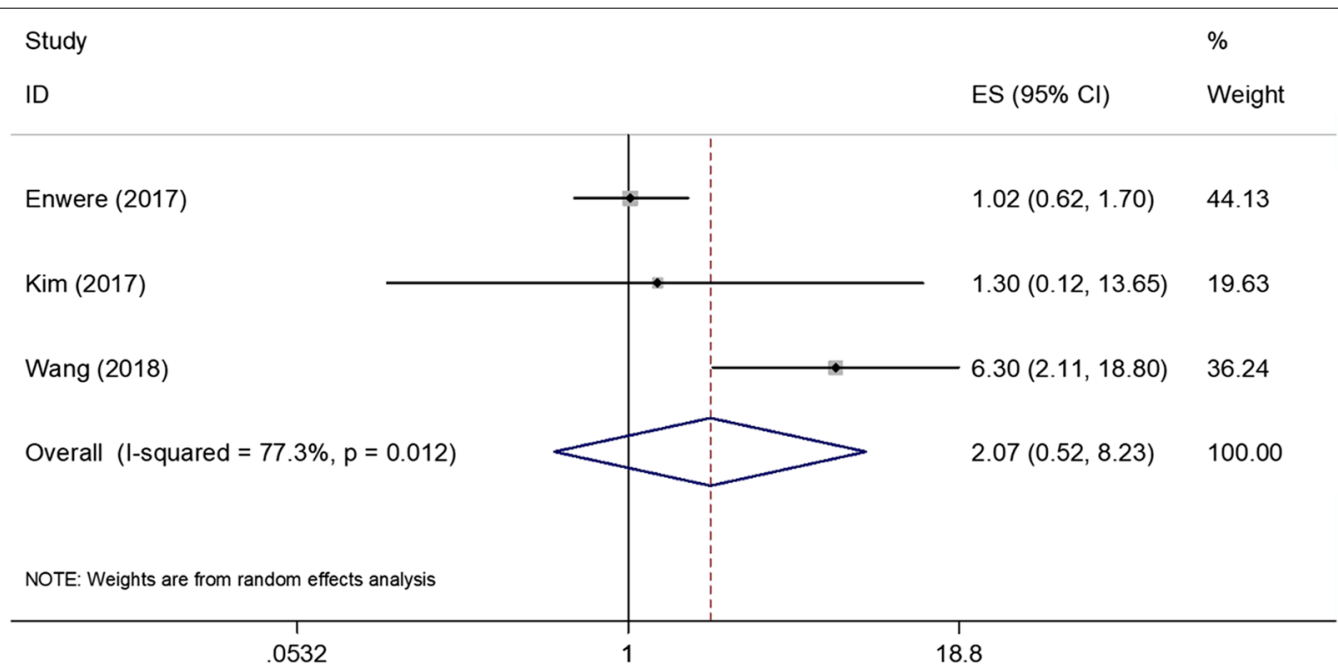

Fig. 3 Forest plot showing pooled hazard ratio for PFS and PD-L1 expression in cervical cancer 
of PD-L1 was a significant prognostic factor of poor OS in Asian patients $(\mathrm{HR}=4.77,95 \% \mathrm{CI}=3.02-7.54$, $\mathrm{p}<0.001)$, but not in Caucasian patients $(\mathrm{HR}=1.13,95 \%$ $\mathrm{CI}=0.68-1.88, \mathrm{p}=0.634$ ) (Table 2). In addition, PD-L1 was also a significant marker of OS in studies with sample $<100(\mathrm{HR}=5.01,95 \% \mathrm{CI}=1.93-13.03, \mathrm{p}=0.001)$ and patients receiving surgery $(\mathrm{HR}=3.04,95 \% \mathrm{CI}=1.42-$ 6.48, $\mathrm{p}=0.004)$. However, PD-L1 was not significantly associated with poor OS in studies with sample $\geq 100$ or patients receiving non-surgery treatment. As for PFS, the subgroup analysis indicated that PD-L1 showed significant prognostic value in Asian patients $(\mathrm{HR}=4.78,95 \%$ $\mathrm{CI}=1.77-12.91, \mathrm{p}=0.002)$ (Table 2).

\section{Correlation of PD-L1 expression with clinicopathological characteristics}

To identify the impact of PD-L1 on clinicopathological characteristics of cervical cancer, we investigated the association between PD-L1 overexpression with six factors. As shown in Table 3 and Fig. 4, the pooled results suggested that PD-L1 was not significantly correlated with lymph node metastasis $(\mathrm{n}=7, \mathrm{OR}=1.15,95 \%$ $\mathrm{CI}=0.59-2.25, \mathrm{p}=0.682)$, tumor size $(\mathrm{n}=6, \mathrm{OR}=1.48$, $95 \% \mathrm{CI}=0.71-3.08, \mathrm{p}=0.294), \quad$ FIGO stage $(\mathrm{n}=6$, $\mathrm{OR}=1.18,95 \% \mathrm{CI}=0.83-1.68, \mathrm{p}=0.345)$, depth of invasion $(\mathrm{n}=5, \mathrm{OR}=0.85,95 \% \mathrm{CI}=0.4-1.82, \mathrm{p}=0.674)$, lymph-vascular invasion $(\mathrm{n}=5, \quad \mathrm{OR}=0.84, \quad 95 \%$ $\mathrm{CI}=0.57-1.22, \mathrm{p}=0.357)$, or age $(\mathrm{n}=3, \mathrm{OR}=1.14,95 \%$ $\mathrm{CI}=0.74-1.77, \mathrm{p}=0.554)$.

\section{Publication bias}

Begg's funnel plots and Egger's linear regression test were used to evaluate the publication bias of the eligible studies. The results showed that no significant publication bias was detected for OS (Begg's $\mathrm{p}=0.548$, Egger's $\mathrm{p}=0.798$, Fig. 5) or PFS (Begg's

Table 2 Subgroup analysis of PD-L1 and OS, PFS in cervical cancer

\begin{tabular}{|c|c|c|c|c|c|c|}
\hline Factors & No. of studies & Effects model & $\mathrm{HR}(95 \% \mathrm{Cl})$ & $p$ & $\begin{array}{l}\text { Heterogeneity } \\
I^{2}(\%) \mathrm{Ph}\end{array}$ & \\
\hline \multicolumn{7}{|l|}{ OS } \\
\hline Total & 7 & Random & $2.52(1.09-5.83)$ & 0.031 & 73 & 0.001 \\
\hline \multicolumn{7}{|l|}{ Ethnicity } \\
\hline Asian & 5 & Fixed & $4.77(3.02-7.54)$ & $<0.001$ & 18 & 0.3 \\
\hline Caucasian & 2 & Fixed & $1.13(0.68-1.88)$ & 0.634 & 0 & 0.562 \\
\hline \multicolumn{7}{|l|}{ Sample size } \\
\hline$<100$ & 3 & Fixed & $5.01(1.93-13.03)$ & 0.001 & 0 & 0.471 \\
\hline$\geq 100$ & 4 & Random & $1.75(0.55-5.59)$ & 0.344 & 83.7 & $<0.001$ \\
\hline \multicolumn{7}{|l|}{ Treatment } \\
\hline Surgery & 5 & Fixed & $3.04(1.42-6.48)$ & 0.004 & 36.6 & 0.177 \\
\hline Non-surgery & 2 & Random & $2.29(0.51-10.34)$ & 0.28 & 93.6 & $<0.001$ \\
\hline \multicolumn{7}{|l|}{ PFS } \\
\hline Total & 3 & Random & $2.07(0.52-8.23)$ & 0.302 & 77.3 & 0.012 \\
\hline \multicolumn{7}{|l|}{ Ethnicity } \\
\hline Asian & 2 & Fixed & $4.78(1.77-12.91)$ & 0.002 & 28.7 & 0.236 \\
\hline Caucasian & 1 & NA & $1.02(0.62-1.69)$ & 0.939 & NA & NA \\
\hline
\end{tabular}

OS, overall survival; PFS, progression-free survival; NA, not available

Table 3 Associations between PD-L1 and clinical factors in cervical cancer

\begin{tabular}{|c|c|c|c|c|c|c|c|c|}
\hline Clinical factors & $\begin{array}{l}\text { No. } \\
\text { of studies }\end{array}$ & Effects model & OR $(95 \% \mathrm{Cl})$ & $\mathbf{p}$ & $\begin{array}{l}\text { Hete } \\
I^{2}(\%\end{array}$ & eneity & Begg's p & Egger's p \\
\hline Lymph node metastasis (yes vs no) & 7 & Random & $1.15(0.59-2.25)$ & 0.682 & 63.6 & 0.011 & 0.368 & 0.543 \\
\hline Tumor size $(\mathrm{mm})(\geq 40 \mathrm{vs}<40)$ & 6 & Random & $1.48(0.71-3.08)$ & 0.294 & 67.5 & 0.009 & 0.707 & 0.93 \\
\hline FIGO stage (II vs I) & 6 & Fixed & $1.18(0.83-1.68)$ & 0.345 & 39.9 & 0.139 & 0.707 & 0.85 \\
\hline Depth of invasion (mm) $(\geq 10 \mathrm{vs}<10)$ & 5 & Random & $0.85(0.4-1.82)$ & 0.674 & 60.6 & 0.038 & 0.221 & 0.062 \\
\hline Lymph-vascular invasion (yes vs no) & 5 & Fixed & $0.84(0.57-1.22)$ & 0.357 & 11.4 & 0.341 & 1 & 0.758 \\
\hline $\operatorname{Age}(y)(\geq 45$ vs $<45)$ & 3 & Fixed & $1.14(0.74-1.77)$ & 0.554 & 22.7 & 0.274 & 0.296 & 0.24 \\
\hline
\end{tabular}

FIGO, The International Federation of Gynecology and Obstetrics 


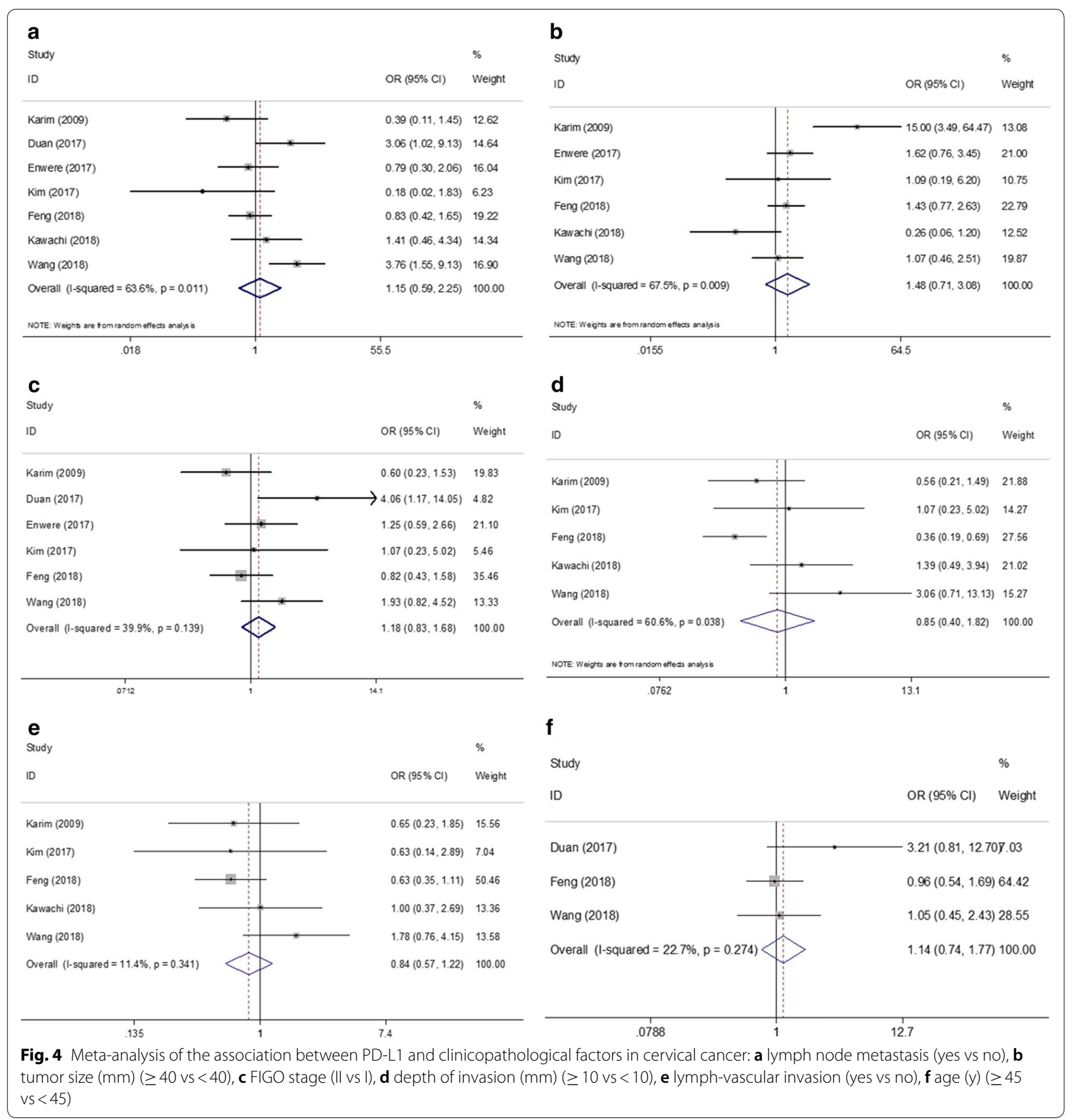

$\mathrm{p}=1$, Egger's $\mathrm{p}=0.638$, Fig. 5). The results of publication bias for PD-L1 and clinicopathological characteristics were listed in Table 3. All p-values of publication bias were $>0.05$, indicating the credibility of this meta-analysis.

\section{Discussion}

The present meta-analysis is the first to evaluate the association between PD-L1 overexpression and survival in patients with cervical cancer. In this study, we pooled the data from 7 eligible studies with 783 patients and found 


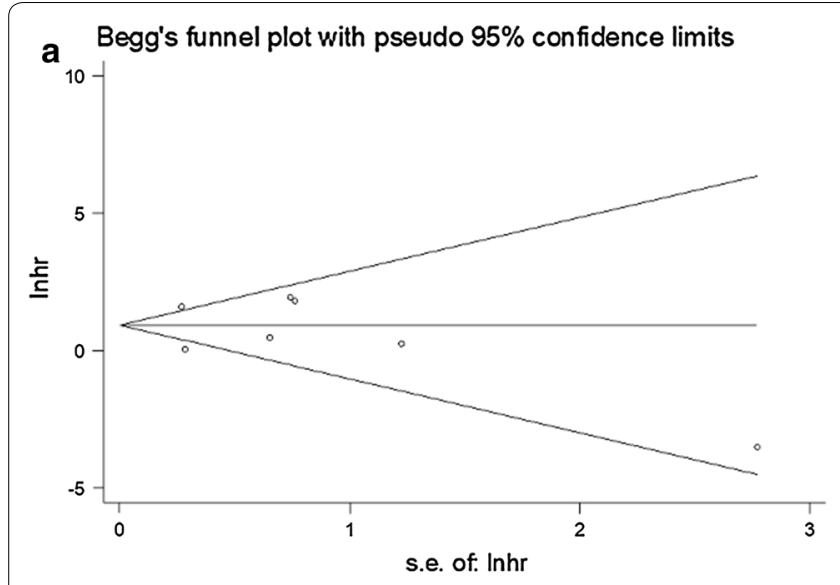

C Begg's funnel plot with pseudo $95 \%$ confidence limits
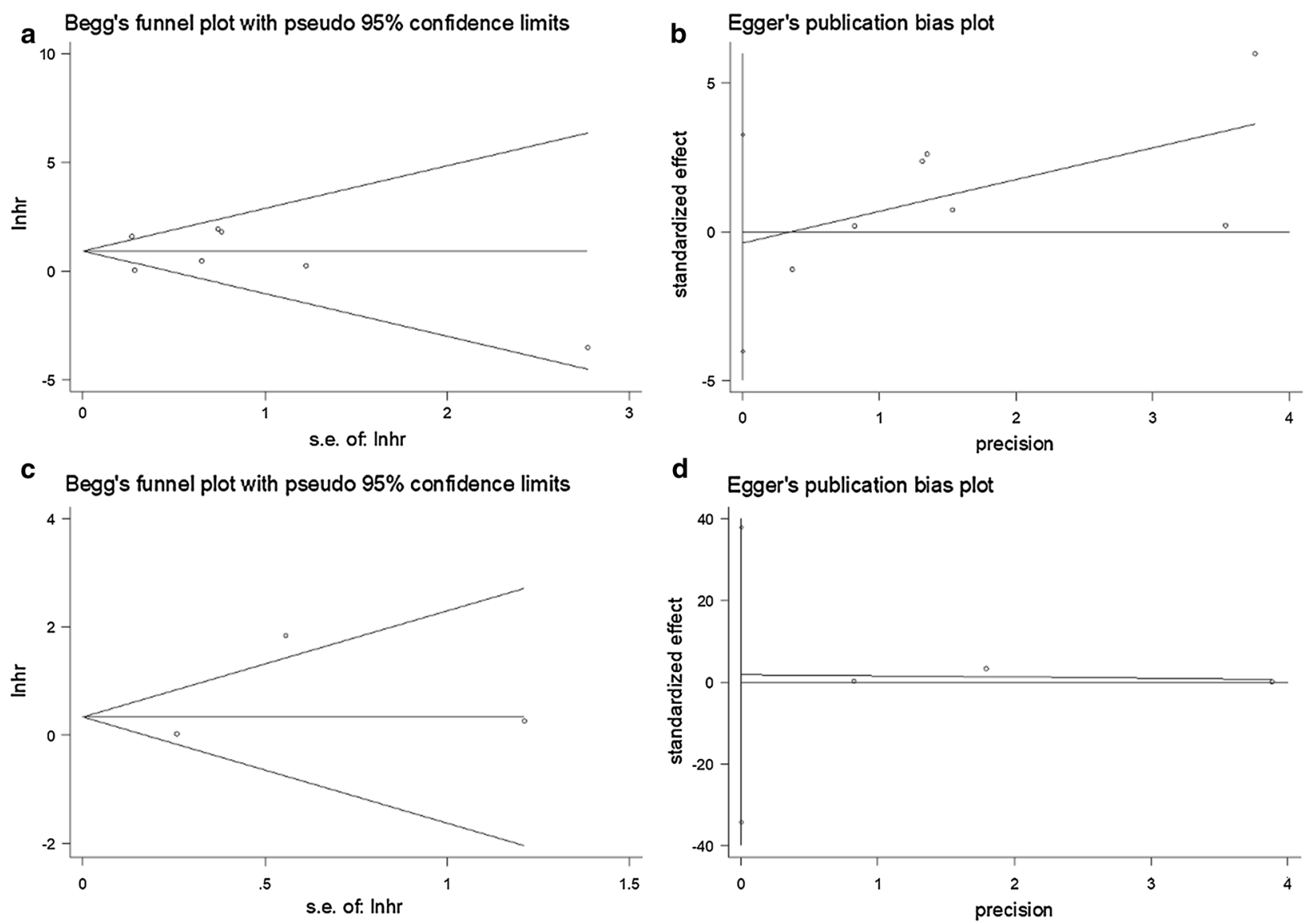

Fig. 5 Publication bias. a Begg's test for OS ( $p=0.548)$, b Egger's test for OS $(p=0.798)$, $\mathbf{c}$ Begg's test for PFS $(p=1)$, d Egger's test for PFS ( $p=0.638)$

that PD-L1 was a significant prognostic factor for poor OS, but not for PFS. Further subgroup analysis revealed that PD-L1 overexpression had enhanced prognostic function of poor OS in Asian patients, moreover, PD-L1 also indicated poor PFS in Asian patients. Nevertheless, the correlation of PD-L1 and several clinicopathological features were not statistically significant, which might imply the clinical roles of PD-L1 in cervical cancer diagnosis.

PD-L1 is an important immune regulatory molecule that was reported to be critically involved in the immune escape mechanism of various cancer cells [24]. In many solid tumors, the overexpression of PD-L1 can lead to immunosuppressive tumor microenvironment and prevent cell-mediated lysis. In addition, the expression of PD-1 in tumor infiltrating lymphocytes is another key point of immune escape mediated by PD-1/PD-L1 [25]. Interaction of PD-1/PD-L1 results in blocking $\mathrm{T}$ cell activation and inhibiting TCR signal transduction and CD28-CD80 co-stimulation [26]. PD-L1 is also expressed in activated immune cells including dendritic cells, macrophages, B cells, $\mathrm{T}$ cells and natural killer cells [27].
Previous studies also investigated the prognostic role of PD-L1 in various solid tumors. A recent study [28] demonstrated that expression level of PD-L1 was associated with the $\mathrm{OS}$ in gastric cancer $(\mathrm{HR}=1.46,95 \%$ $\mathrm{CI}=1.08-1.98, \mathrm{p}=0.01)$. A previous work conducted by $\mathrm{Ni}$ et al. also showed that the pooled HR of (1.34, 95\% CI 1.02-1.65, $\mathrm{p}=0.01$ ) indicated the association of PD-L1 expression with OS in colorectal cancer patients [29]. Additionally, Ni's study also reported the expression of PD-L1 was positively correlated with the lymph node metastasis in colorectal cancer [29]. The prognostic value was also presented in other solid malignancies including prostate cancer [30], esophageal squamous cell carcinoma [31], glioma [32], Osteosarcoma [33], and non-small cell lung cancer [34]. The results of the present meta-analysis were in line with the results of other types of cancer. The present study is the first meta-analysis on PD-L1 and cervical cancer to date. Previous meta-analyses $[35,36]$ on PD-L1 and survival in solid tumors only included one study [12] of cervical cancer, the results provided limited information on the prognostic value of PD-L1 in cervical cancer. Therefore, our meta-analysis 
was comprehensive and convincing. A recent study [37] systematically reviewed the present and ongoing clinical researches on PD-1/PD-L1 inhibitors in cervical cancer. The patients showed favorable objective response rate (ORR) and disease control with PD-1/PD-L1 inhibitors treatment. We highlight the importance of survival as the primary evaluation endpoint in clinical trials on PD-1/ PD-L1 inhibitors in cervical cancer. Furthermore, in the present study, our results that PD-L1 overexpression predicts worse OS might provide implications for future clinical design and assessment.

There are some limitations to this study that should be acknowledged. First, the sample size was relatively small. Although 7 studies were included for analysis, the total sample size was 783 , the limited amount may compromise the generality of the results. Second, only articles published in English and Chinese were included in this meta-analysis. Because of our restriction of availability to articles published in other languages, the studies from other countries may be neglected. Third, there may be inconsistent data in the included studies, as they used different cutoff values for identifying PD-L1 overexpression.

\section{Conclusions}

This meta-analysis demonstrated that PD-L1 overexpression is related to poor OS in patients with cervical cancer and poor PFS in Asian patients with cervical cancer. PD-L1 overexpression had non-significant association with clinical characteristics in cervical cancer. This study also suggests that PD-L1 is a promising prognostic indicator for cervical cancer. Due to abovementioned limitations, further large-scale prospective studies are needed to warrant the results.

\section{Abbreviations \\ PD-L1: programmed cell death ligand 1; OS: overall survival; PFS: progression- free survival; HR: hazard ratio; OR: odds ratios; Cl: confidence interval; LMIC: low income and middle-income countries; PRISMA: Preferred Reporting Items for Systematic Reviews and Meta-Analyses; MeSH: Medical Subject Headings; IHC: immunohistochemistry; FIGO: The International Federation of Gynecol- ogy and Obstetrics.}

\section{Acknowledgements}

We would like to thank the researchers and study participants for their contributions.

\section{Authors' contributions}

$X G, M D, Y Z$, and SD collected, extracted and analyzed the data, wrote the paper; YM, JY, ZL, ZZ, KL, and LJ performed quality assessment and analyzed the data. $X G$ and $Y S$ conceived and designed this study. All authors reviewed the paper. All authors read and approved the final manuscript.

\section{Funding}

This work was supported by Grants of Key Scientific Research Projects of Universities in Henan Province (No. 17A320066).

Availability of data and materials

Please contact author for data requests.
Ethics approval and consent to participate Not applicable.

\section{Consent for publication}

Not applicable.

\section{Competing interests}

The authors declare that they have no competing interests.

Received: 27 March 2019 Accepted: 13 May 2019

Published online: 23 May 2019

\section{References}

1. Bray F, Ferlay J, Soerjomataram I, Siegel RL, Torre LA, Jemal A. Global cancer statistics 2018: GLOBOCAN estimates of incidence and mortality worldwide for 36 cancers in 185 countries. CA Cancer J Clin. 2018;68(6):394-424.

2. Arbyn M, Castellsague X, de Sanjose S, Bruni L, Saraiya M, Bray F et al. Worldwide burden of cervical cancer in 2008. Ann Oncol. 2011;22(12):2675-86

3. Hansen JD, Du Pasquier L, Lefranc MP, Lopez V, Benmansour A, Boudinot P. The B7 family of immunoregulatory receptors: a comparative and evolutionary perspective. Mol Immunol. 2009;46(3):457-72.

4. Wang PF, Chen Y, Song SY, Wang TJ, Ji WJ, Li SW, et al. Immune-related adverse events associated with anti-PD-1/PD-L1 treatment for malignancies: a meta-analysis. Front Pharmacol. 2017;8:730.

5. Tumeh PC, Harview CL, Yearley JH, Shintaku IP, Taylor EJ, Robert L, et al. PD-1 blockade induces responses by inhibiting adaptive immune resistance. Nature. 2014;515(7528):568-71.

6. Sharma P, Allison JP. The future of immune checkpoint therapy. Science. 2015;348(6230):56-61.

7. Wang CJ, Zhu HJ, Zhou YD, Mao F, Lin Y, Pan B, et al. Prognostic value of PD-L1 in breast cancer: a meta-analysis. Breast Journal. 2017;23(4):436-43.

8. Pan ZK, Ye F, Wu X, An HX, Wu JX. Clinicopathological and prognostic significance of programmed cell death ligand1 (PD-L1) expression in patients with non-small cell lung cancer: a meta-analysis. J Thor Dis. 2015;7(3):462-70.

9. Zhuan-Sun YX, Huang FT, Feng M, Zhao XB, Chen WY, Zhu Z, et al. Prognostic value of PD-L1 overexpression for pancreatic cancer: evidence from a meta-analysis. Oncotargets Ther. 2017;10:5005-12.

10. Xu F, Xu LL, Wang Q, An GY, Feng GS, Liu FQ. Clinicopathological and prognostic value of programmed death ligand-1 (PD-L1) in renal cell carcinoma: a meta-analysis. Int J Clin Exp Med. 2015;8(9):14595-603.

11. Zhang MH, Dong YD, Liu HT, Wang Y, Zhao S, Xuan QJ, et al. The clinicopathological and prognostic significance of PD-L1 expression in gastric cancer: a meta-analysis of 10 studies with 1,901 patients. Sci Rep. 2016;6:1.

12. Karim R, Jordanova ES, Piersma SJ, Kenter GG, Chen L, Boer JM, et al. Tumor-expressed B7-H1 and B7-DC in relation to PD-1 + T-cell infiltration and survival of patients with cervical carcinoma. Clin Cancer Res. 2009;15(20):6341-7.

13. Enwere EK, Kornaga EN, Dean M, Koulis TA, Phan T, Kalantarian M, et al. Expression of PD-L1 and presence of CD8-positive T cells in pre-treatment specimens of locally advanced cervical cancer. Modern Pathol. 2017:30(4):577-86.

14. Kim M, Kim H, Suh DH, Kim K, Kim H, Kim YB, et al. Identifying rational candidates for immunotherapy targeting PD-1/PD-L1 in cervical cancer. Anticancer Res. 2017;37(9):5087-94.

15. Kawachi A, Yoshida H, Kitano S, Ino Y, Kato T, Hiraoka N. Tumor-associated CD204(+) M2 macrophages are unfavorable prognostic indicators in uterine cervical adenocarcinoma. Cancer Sci. 2018;109(3):863-70.

16. Moher D, Liberati A, Tetzlaff J, Altman DG, Grp P. Preferred reporting items for systematic reviews and meta-analyses: the PRISMA statement. Ann Intern Med. 2009;151(4):264.

17. Tierney JF, Stewart LA, Ghersi D, Burdett S, Sydes MR. Practical methods for incorporating summary time-to-event data into meta-analysis. Trials. 2007;8:16. 
18. Stang A. Critical evaluation of the Newcastle-Ottawa scale for the assessment of the quality of nonrandomized studies in meta-analyses. Eur J Epidemiol. 2010;25(9):603-5.

19. Begg CB, Mazumdar M. Operating characteristics of a rank correlation test for publication bias. Biometrics. 1994;50(4):1088-101.

20. Egger M, Smith GD, Schneider M, Minder C. Bias in metaanalysis detected by a simple, graphical test. Bmj Br Med J. 1997;315(7109):629-34.

21. Duan W, Sui JD, Li Q, Li MX, Yang YX, He L, et al. Expression and clinical significance of PD-L1 and APE1 in early cervical squamous cell carcinoma. J Third Mil Med Univ. 2017;39(1):84-8.

22. Feng $M, X u L, H e Y$, Sun $L$, Zhang $Y$, Wang W. Clinical significance of PD-L1 (CD274) enhanced expression in cervical squamous cell carcinoma. Int J Clin Exp Pathol. 2018;11(11):5370-8.

23. Wang SJ, Li JJ, Xie J, Liu F, Duan YC, Wu Y, et al. Programmed death ligand 1 promotes lymph node metastasis and glucose metabolism in cervical cancer by activating integrin beta 4/SNAI1/SIRT3 signaling pathway. Oncogene. 2018;37(30):4164-80.

24. Pardoll DM. The blockade of immune checkpoints in cancer immunotherapy. Nat Rev Cancer. 2012:12(4):252-64.

25. Azuma T, Yao S, Zhu G, Flies AS, Flies SJ, Chen L. B7-H1 is a ubiquitous antiapoptotic receptor on cancer cells. Blood. 2008;111(7):3635-43.

26. Riley JL. PD-1 signaling in primary T cells. Immunol Rev. 2009;229:114-25.

27. Matta BM, Raimondi G, Rosborough BR, Sumpter TL, Thomson AW. IL-27 production and STAT3-dependent upregulation of B7-H1 mediate immune regulatory functions of liver plasmacytoid dendritic cells. J Immunol. 2012:188(11):5227-37.

28. Gu LH, Chen MM, Guo DY, Zhu HP, Zhang WC, Pan JH, et al. PD-L1 and gastric cancer prognosis: a systematic review and meta-analysis. PLoS ONE. 2017;12:8.

29. Ni X, Sun X, Wang D, Chen Y, Zhang Y, Li W, et al. The clinicopathological and prognostic value of programmed death-ligand 1 in colorectal cancer: a meta-analysis. Clin Transl Oncol. 2018. https://doi.org/10.1007/s1209 4-018-1970-9.

30. Li Y, Huang QY, Zhou YY, He MZ, Chen JH, Gao YB, et al. The clinicopathologic and prognostic significance of programmed cell death ligand 1 (PD-L1) expression in patients with prostate cancer: a systematic review and meta-analysis. Front Pharmacol. 2019;9:3197.

31. Qu HX, Zhao LP, Zhan SH, Geng CX, Xu L, Xin YN, et al. Clinicopathological and prognostic significance of programmed cell death ligand 1 (PD-L1) expression in patients with esophageal squamous cell carcinoma: a meta-analysis. J Thor Dis. 2016;8(11):3197-204.

32. Xue S, Song G, Yu JM. The prognostic significance of PD-L1 expression in patients with glioma: a meta-analysis. Sci Rep. 2017;7:4231.

33. Huang $X$, Zhang WY, Zhang ZC, Shi DY, Wu FS, Zhong BL, et al. Prognostic value of programmed cell death 1 ligand-1 (PD-L1) or PD-1 expression in patients with osteosarcoma: a meta-analysis. J Cancer. 2018;9(14):2525-31.

34. Wang A, Wang HY, Liu Y, Zhao MC, Zhang HJ, Lu ZY, et al. The prognostic value of PD-L1 expression for non-small cell lung cancer patients: a metaanalysis. Ejso. 2015;41(4):450-6.

35. Wang QQ, Liu F, Liu L. Prognostic significance of PD-L1 in solid tumor an updated meta-analysis. Medicine. 2017;96(18):e6369.

36. Wu P, Wu D, Li LJ, Chai Y, Huang J. PD-L1 and survival in solid tumors: a meta-analysis. PLoS ONE. 2015;10(6):e0131403.

37. Liu Y, Wu L, Tong R, Yang F, Yin L, Li M, et al. PD-1/PD-L1 inhibitors in cervical cancer. Front Pharmacol. 2019;10:65.

\section{Publisher's Note}

Springer Nature remains neutral with regard to jurisdictional claims in published maps and institutional affiliations.
Ready to submit your research? Choose BMC and benefit from:

- fast, convenient online submission

- thorough peer review by experienced researchers in your field

- rapid publication on acceptance

- support for research data, including large and complex data types

- gold Open Access which fosters wider collaboration and increased citations

- maximum visibility for your research: over $100 \mathrm{M}$ website views per year

At $\mathrm{BMC}$, research is always in progress.

Learn more biomedcentral.com/submissions 